\title{
Surface ultrastructure of Blastocystis sp. isolated from cattle
}

\section{NI KOMANG APRILINA WIDISUPUTRI ${ }^{1}$, NUNUK DYAH RETNO LASTUTI ${ }^{1}$, ENDANG SUPRIHATI $^{1}$, POEDJI HASTUTIEK $^{1}$, HANI PLUMERIASTUTI ${ }^{2}$, MUFASIRIN ${ }^{1,3}$, HENI PUSPITASARI $^{3}$, LUCIA TRI SUWANTI $I^{1,3, v}$}

\author{
${ }^{1}$ Department of Veterinary Parasitology, Faculty of Veterinary Medicine, Universitas Airlangga. Jl. Mulyorejo, Kampus C Unair, Surabaya 60115, East \\ Java, Indonesia \\ ${ }^{2}$ Department of Veterinary Patology, Faculty of Veterinary Medicine, Universitas Airlangga. Jl. Mulyorejo, Kampus C Unair, Surabaya 60115, East Java, \\ Indonesia \\ ${ }^{3}$ Institute of Tropical Disease, Universitas Airlangga. Jl. Mulyorejo, Kampus C Unair, Surabaya, 60115, East Java, Indonesia. \\ Tel./fax.: +62 31-5992785, `email: lucia-t-s@fkh.unair.ac.id
}

Manuscript received: 4 January 2021. Revision accepted: 26 February 2021.

\begin{abstract}
Widisuputri NKA, Lastuti NDR, Suprihati E, Hastutiek P, Plumeriastuti H, Mufasirin, Puspitasari H, Suwanti LT. 2021. Surface ultrastructure of Blastocystis sp. isolated from cattle. Biodiversitas 22: 1514-1518. Blastocystis sp is a protozoan parasite commonly detected in the intestinal tract of humans and various animals that causes zoonotic blastocystosis. The pathogenic potential of Blastocystis is still being evaluated, some Blastocystis sp are completely pathogenic, while others can be considered commensal and hypothetical, related to the role of the surface coat of Blastocystis sp. This study aimed to compare the surface ultrastructure of Blastocystis sp. in cattle with diarrhea and non diarrhea by Scanning Electron Microscope (SEM). Four Blastocystis sp. isolates were selected from the faeces of four positives cattle which consisted of two diarrhea and two non-diarrhea cattle. The result showed that Blastocystis sp. in cattle appeared in round shape and reproduced by binary fission. The surface cell of Blastocystis sp. isolates from diarrhea cattle had a rough surface while organism of non diarrhea cattle isolates was very smooth. Bacteria were seen attached to the surface of Blastocystis sp. from diarrhea cattle faeces. In conclusion, the features of the surface structure of Blastocystis sp. correlated with symptomatic appearance. The surface structure of Blastocystis sp. isolates from cattle with diarrhea was rougher than non diarrhea.
\end{abstract}

Keywords: Blastocystis, cattle with diarrhea, scanning electron microscope, surface structure

\section{INTRODUCTION}

Blastocystis sp. is a protozoan parasite that commonly found in the intestinal tract of humans and varied of animals and its infection caused blastocystosis (Wawrzyniak et al. 2013). Animals that were infected include mammals, birds, amphibians, and reptiles (Cian et al. 2017). In recent years, researches on the identification and prevalence of Blastocystis sp. both in humans and animals have been reported throughout the world (Lee et al. 2012) and several studies have shown that Blastocystis infection is zoonotic, this is evidenced by the discovery of the same subtype (ST) in humans and animals (Osman et al. 2016). Blastocystis infection is a waterborne or foodborne disease, and oral transmission occurs due to ingestion of the infective stage, cysts, which contaminate water and food (Lee et al. 2012). The prevalence of Blastocystis infection in humans in developing countries is significantly higher than in developed countries (El Safadi et al. 2016). Poor hygiene practices, close contact with animals, and consumption of contaminated food or water are factors in the high prevalence of blastocystosis in people (Wawrzyniak et al. 2013). Symptoms of blastocystosis are non-specific such as diarrhea, abdominal pain, constipation, flatulence, fatigue, urticaria and skin rash (Parija and Jeremiah 2013; Wawrzyniak et al. 2013) and most of cases are asymptomatic (Yason and Tan 2018). Some researchers found Blastocystis sp both in the host with or without clinical symptoms, this is the reason why the pathogenicity of Blastocystis is still being (Roberts et al. 2014; Skotarczak 2018). However, some researchers point to serious consequences due to this parasitic infection, in which, Blastocystis sp. was known to play a role in irritable bowel syndrome (IBS) (Ragavan et al. 2014 ; 2015) and induced precancerous polyp formation (Kumarasamy et al. 2017).

Diagnose of Blastocystis sp. generally based on the morphologically parasite in faeces by direct examination using the light microscope or by in vitro cultivation method. Blastocystis sp. is morphologically in the form of vacuoles, granular, amoeboid, or cysts (Wawrzyniak et al. 2013), but the morphology of Blastocystis sp. isolates from humans and animals, is difficult to be distinguished only by light microscopy examination, as they were morphologically similar (Zhang et al. 2012). Previous study by Suwanti et al. (2020a) reported thatthe morphology of Blastocystis sp. in cattle were varied widely in size with $2.78-35.35 \mu \mathrm{m}$ (average14.76 $\mu \mathrm{m}$ ) in which $100 \%$ of the cattle samples were positive for Blastocystis however differentiation between diarrhea and non-diarrheal cattle were not considered.

Examination using an electron microscope recently shed new light on the morphology of parasites, one of which by using Scanning Electron Microscope (SEM). Using SEM aimed to obtain detailed information on the morphology and topography of the cell surface of a 
microorganism (de Souza and Attias 2018). Research on surface ultrastructure Blastocystis sp. using SEM has been reported in humans, monkeys, pigs, chickens, rats and cockroaches which have varying $d$ ifferences in their surface coat (Cassidy et al. 1994; Haziqah et al. 2017). According to Yason and Tan (2018), electron micrographs showed variations in the surface coats from the different Blastocystis isolates and these differences could be attributed to differences in the pathogenic potential of the Blastocystis subtype. It has also been proven by Ahmed et al. (2019) that the surface ultrastructure of Blastocystis sp. was rougher in isolates from patients with colorectal carcinoma.

Until now, the research of surface ultrastructure of Blastocystis sp. in cattle has not been reported. As already mentioned above, the results of previous studies showed the morphology of Blastocystis sp. in cattle with diarrhea and no diarrhea were the same. The aim of this study was to compare the surface structure of Blastocystis from cultured faeces samples of cattle with (symptomatic) and no diarrhea (asymptomatic) using SEM.

\section{MATERIALS AND METHODS}

\section{Ethical approval}

Ethical approval for this study was granted by the Animal Care and Use Committee of the Faculty of Veterinary Medicine, Universitas Airlangga (approval number: 2.KE. 095.05.2019)

\section{Isolate of Blastocystis sp}

Isolate was Blastocystis sp. isolated from the feces of Madura cattle in Kamal and Socah, Bangkalan, Madura, Indonesia. Isolation was carried out in 2018, by taking samples of fresh feces that had just fallen to the ground. A total of 108 samples were examined. The presence of Blastocystis sp. in feces was detected by both morphologically and genetically based on the 18S rRNA gene (Suwanti et al. 2020b). The Isolate were stored in the Department of Veterinary Parasitology, Faculty of Veterinary Medicine, Universitas Airlangga.

\section{In Vitro Cultivation}

Four Blastocystis sp. isolates were subcultured from four positive cattle samples consisting of two diarrhea and two non-diarrhea cattle. Each sample was cultured in RPMI 1640 medium (CP19-2763, Capricorn Saintific, Germany) and incubated at $37^{\circ} \mathrm{C}$ for 3 days. The growth of Blastocystis sp. in culture was observed morphologically under a light microscope (Nikon ${ }^{\circledR}$ E100, Japan) at $400 \mathrm{X}$ magnification. Microscope was connected to a camera (Optilab® MTN001, Indonesia) to capture the image of the parasites. The supernatant of the culture medium was inserted into the tube and centrifuged at $1500 \mathrm{rpm}$ for 10 minutes. Supernatant was removed and pellets was resuspended with phosphate buffered saline (PBS) and stored for SEM observation.

\section{Scanning Electron Microscope (SEM)}

Cell of Blastocystis sp. were washed with PBS pH 7 forthree times by centrifugation. It was centrifugated with speed $3000 \mathrm{rpm}$ for 5 minutes. Then each sample was fixed by adding $2.5 \%$ glutaraldehyde and post-fixation with $1 \%$ osmium tetroxide. The isolate was mounted on a polycarbonate membrane and dehydrated using ethanol in sequence $30 \%, 50 \%, 70 \%, 80 \%, 90 \%$, and 100\%. Each ethanol series was done for 15 minutes and the last step was added with amyl acetate. Critical Point Drying (CPD) was performed using carbon dioxide, then the specimen was coated using a gold coating, and observed using SEM (Ragavan et al. 2014). SEM images were captured at the Faculty of Mechanical Engineering, Institut Teknologi Sepuluh November (ITS) Surabaya.

\section{RESULTS AND DISCUSSION}

\section{Morphology of Blastocystis in medium culture}

On culture media Blastocystis sp. most of the vacuolar forms (Figure 1). In previous study, it was found that the diameter of Blastocystis sp. in cattles was varied widely with ranged about 2.78 to $35.35 \mu \mathrm{m}$ (average $14.76 \mu \mathrm{m}$ ) and the size of Blastocystis sp. in culture was smaller than in fresh stool (Suwanti et al. 2020a). The main morphology of Blastocystis sp. has four forms: vacuole, granular, amoeboid and cyst form (Wawrzyniak et al. 2013) and the vacuolar form was the most common cell form found in cultures (Natalia et al. 2018). Under a light microscope, the morphology of Blastocystis sp. from healthy cattle (without diarrhea) and diarrhea cattle could not be distinguished. According to Tan et al. (2008), Blastocystis poses considerable challenges for diagnostic laboratories. The morphology of Blastocystis sp. is difficult to distinguish by using light microscopy only (Zhang et al. 2012). Yanson and Tan (2018) using an electron microscope show variations in the membrane surface from three Blastocystis isolates and these differences could be associated with the differences in the pathogenic potential of Blastocystis subtypes.

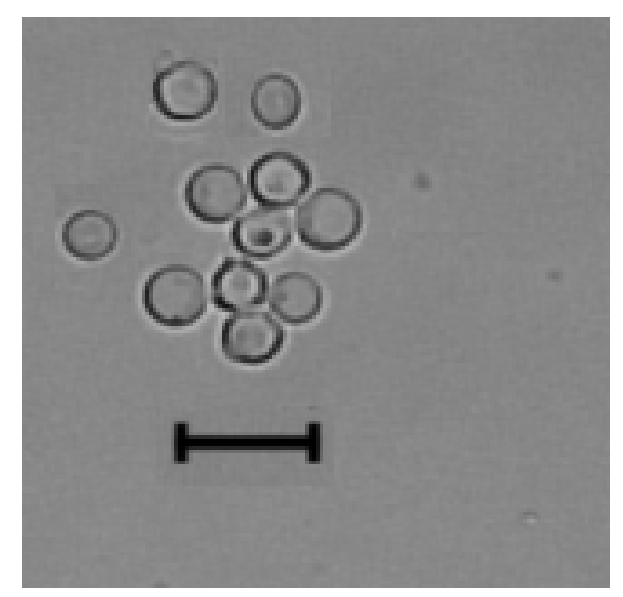

Figure 1. Blastocystis sp. in cattle in medium culture. Bar $10 \mu \mathrm{m}$ 


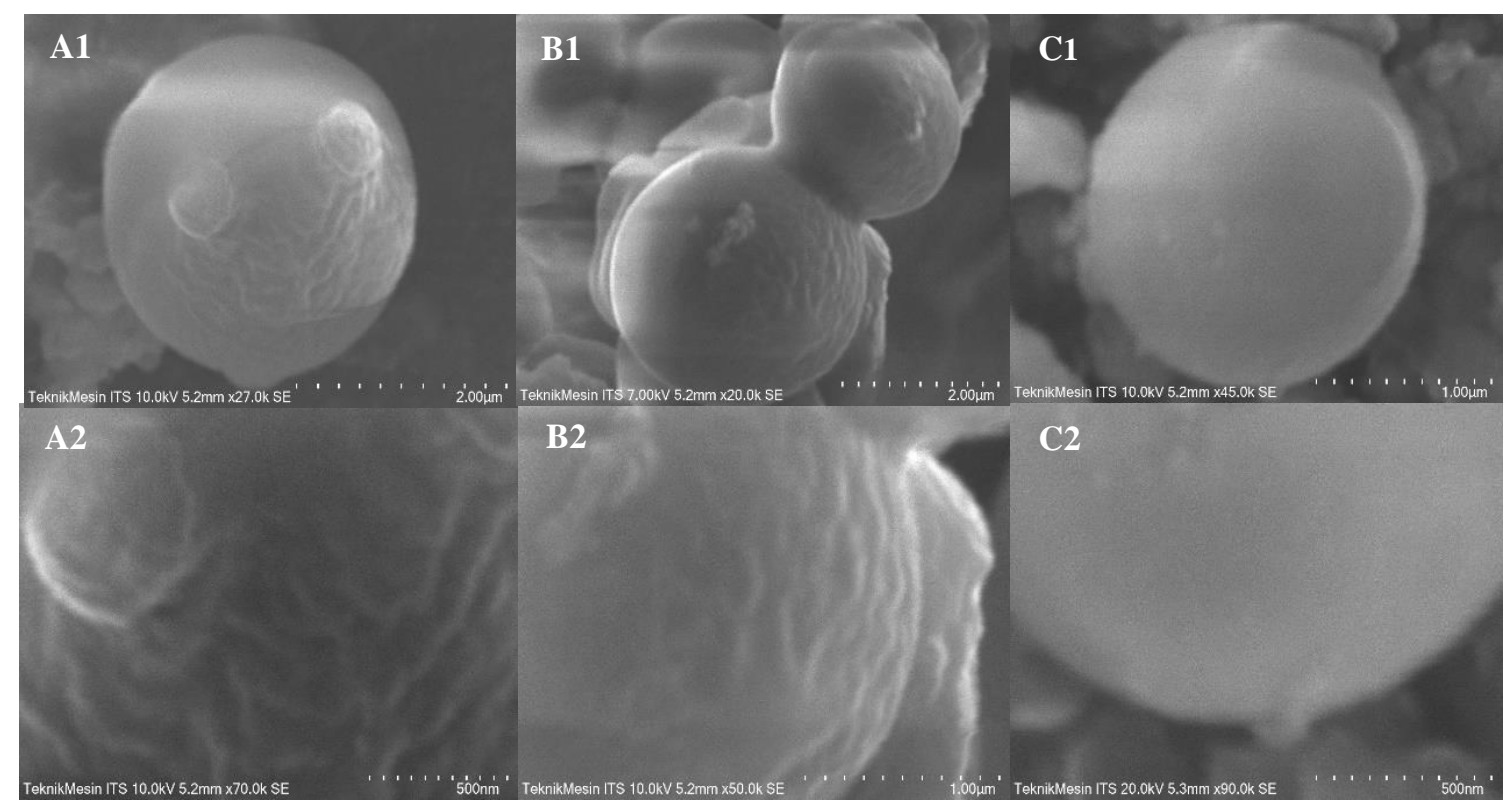

Figure 2. The scanning electron micrograph showing the cell surface of Blastocystis sp.isolated from the in vitro culture. A and B Blastocystis sp. from feces of cattle with diarrhea. C. Blastocystis sp.from faeces of asymptomatic cattle. Red arrows are daughter cell. Black arrows are bacteria.

\section{Appearance of the surface structure of Blastocystis sp. Using SEM}

In this decade, SEM was used widely in the morphological studies of a cell based on the structural surface of the cell, including Blastocystis sp. (Boreham and Stenzel 1993; Zaman et al. 1999; Tan et al. 2008; Zhang et al. 2012; Ragavan et al. 2014; Ahmed et al. 2019). SEM revealed the external morphological shape of the cyst and various surface coat structures of the parasite (Zhang et al. 2012). The surface coat was a kind of fibrous substance in varying appearance, rough or fine, which adhere to the surface of the Blastocystis cells (Elsayad et al. 2019). This study is the first report on the surface structure of Blastocystis sp. in cattle, both in symptomatic (diarrhea) and asymptomatic cattle.

In this study, it was found that Blastocystis sp. in cattle appeared in round shape. This result was similar with the morphology of Blastocystis in human which presented by Boreham and Stenzel (1993), generally the shape of Blastocystisfrom in vitro culture were spherical in shape. Round shape was also found by Ahmed et al. (2019) in addition to other forms, oval and irregular. Blastocystis cells often possess one or two nuclei, and occasionally, quadrinucleate cells and cells possessing numerous nuclei have been reported (Tan 2008). According to Zhang et al. (2007), there were five modes of reproduction, namely, binary fission, endodyogeny, plasmotomy, budding and schizogeny. In this study, the reproduction of blastocystis $\mathrm{sp}$ is shown in Figures 2.A1 and 2.B1. Figure 2.A1 was probably the initial stage of plasmotomy reproduction. Plasmotomy reproduction occurred during the stage of vacuolar form, which a daughter cell came into being by forming a finger-like cytoplasmic extension from the cellular surface of the mother vacuolar cell (Zhang et al.
2007). Figure 2.B1, Blastocystis sp. was seen undergo binary fission similarly reported by Elsayad et al. (2019) and Mehlhorn et al. (2012).

The surface cell of Blastocystis sp. isolates from diarrheal cattle had a rough surface as shown in Figure 2.A and 2.B. Whereas organism of non diarrhea cattle isolates was very smooth (Figure 2.C). Elsayad et al. (2019), using SEM micrographs shown different outer morphology of Blastocystis in human covered by rough or smooth surface coat, but there was no further explanation regarding the differences. The smooth surface structure of Blastocystis sp. isolates from non diarrheal cattle is similar to Blastocystis in asymptomatic human isolates as described previously by Suresh et al. (1994). The rough surface cell illustration in diarrheal cattle in this study supported the results of a study previously reported by Boreham and Stenzel (1993) that rough morphology of cells was found on isolates ofBlastocystis from a diarrhea patient. This cell surface structure may be related to the pathogenicity of organisms related to the symptoms shown. It is suggested that a rough surface Blastocystis is more pathogenic than a smooth surface and the features of the surface structure of Blastocystis sp. correlated with symptomatic appearance. Tan et al. (2008), Ragavan et al. (2014) and Ahmed et al. (2019) stated that there were differences in the surface ultrastructure of Blastocystis isolated from human derivated from symptomatic and asymptomatic persons; Blastocystis from symptomatic isolates have coarser surface structure while asymptomatic isolates have a smooth surface structure. Rougher with excessive indentation surface was drawn from isolates derivated from suffering patients IBS (Ragavan et al. 2014) and colorectal carcinoma (Ahmed et al. 2019). 
Several studies using SEM to observed Blastocystis have indicated that the surface coat is associated with bacteria. The surface coat contains a variety of carbohydrates and has been postulated to play a role in trapping and degrading bacteria for nutrition (Tan 2008). In this study, bacteria were seen attached to the surface of Blastocystis $\mathrm{sp}$. from cattle with diarrhea (Figure 2. $\mathrm{B}_{1}$ ). The attachment of bacteria to the surface of Blastocystis isolated from human samples had been confirmed by SEM studies. Attached bacteria on the surface of Blastocystis have been seen in close association with the surface coat and often causing an indentation (Boreham and Stenzel 1993). Although some surface coat functions are not yet known exactly, it is thought to be a mechanism for trapping bacteria for nutritional purposes and attachment to the intestinal epithelial lining (Zaman et al. 1999) and according to Yason and Tan (2018), the surface coat of Blastocystis sp. associates with potentially pathogenic of Blastocystis subtype. There was a hypothesis that surface coat protects the organism from innate host immune response as well as contribute to greater adhesion during colonization (Yason and Tan 2018).

In conclusion, by SEM, most of Blastocystis sp. isolated from the in vitro cultivation methodof cattle faeces appeared in round shape with and reproduced by binary fission. Meanwhile, the surfaces cell of Blastocystis sp. isolates from cattle with diarrhea had a rough surface while Blastocystis isolated from asymptomatic cattle isolates were having very smooth surface. Bacteria were seen attached to the surface of Blastocystis sp. from cattle with diarrhea. The features of the surface structure of Blastocystis sp. correlated with symptomatic appearance. The surface structure of Blastocystis sp. isolates from cattle with diarrhea was rougher than non diarrhea. Research on the determinants of the pathogenicity of Blastocystis is still needed.

\section{ACKNOWLEDGEMENTS}

The authors wish to express gratitude to Directorate General Research and Development Strengthening of Ministry of Research, Technology and Higher Education, for financial support with research grant through the Budget Execution Checklist 2019-2020.

\section{REFERENCES}

Ahmed MM, Habib FS, Saad GA, El Naggar HM. 2019. Surface ultrastructure, protein profile and zymography of Blastocystis species isolated from patients with colorectal carcinoma. J Parasit Dis 43 (2): 294-303. DOI: 10.1007/s12639-019-01092-9.

Boreham PFL, Stenzel DJ. 1993. Blastocystis in humans and animals morphology, biology, and epizootiology. Adv Parasitol 32: 1-70. DOI: $10.1016 / \mathrm{S} 0065-308 \mathrm{X}(08) 60206-7$.

Cassidy MF, Stenzel DJ, Boreham PF. 1994. Electron microscopy of surface structures of Blastocystis sp. from different hosts. Parasitol Res 80 (6): 505-511. DOI: 10.1007/BF00932698.

Cian A, El Safadi D, Osman M, Moriniere R, Gantois N, Benamrouz Vanneste S, Delgado-Viscogliosi P, Guyot K, Li LL, Monchy S, Noël C. 2017. Molecular epidemiology of Blastocystis sp. in various animal groups from two french zoos and evaluation of potential zoonotic risk. PLoS ONE 12 (1): e0169659. DOI: 10.1371/journal.pone.0169659.

de Souza W, Attias M. 2018. New advances in scanning microscopy and its application to study parasitic protozoa. Exp Parasitol 190: 10-33. DOI: 10.1016/j.exppara.2018.04.018.

Elsayad MH, Tolba MM, Argiah HA, Gaballah A, Osman MM, Mikhael IL. 2019. Electron microscopy of Blastocystis hominis and other diagnostic approaches. J Egypt Soc Parasitol 49 (2): 373-380. DOI: 10.21608/jesp.2019.68145.

El Safadi D, Cian A, Nourrisson C, Pereira B, Morelle C, Bastien P, Bellanger AP, Botterel F, Candolfi E, Desoubeaux G, Lachaud L. 2016. Prevalence, risk factors for infection and subtype distribution of the intestinal parasite Blastocystis sp. from a large-scale multi-center study in France. BMC Infect Dis 16 (1): 451. DOI: 10.1186/s12879016-1776-8.

Haziqah FMT, Asyiqin NMN, Khalid MKN, Suresh K, Rajamanikam A, Chandrawathani P, Mohd Zain SN. 2017. Short Communication: Current status of Blastocystis in cockroaches. Trop Biomed 34 (3): 741-745.

Kumarasamy V, Kuppusamy UR, Jayalakshmi P, Samudi C, Ragavan ND, Kumar S. 2017. Exacerbation of colon carcinogenesis by Blastocystis sp. PLoS ONE 12 (8): e0183097. DOI: 10.1371/journal.pone.0183097.

Lee LI, Chye TT, Karmacharya BM, Govind SK. 2012. Blastocystis sp.: waterborne zoonotic organism, a possibility. Parasites Vectors 5: 130. DOI: $10.1186 / 1756-3305-5-130$.

Mehlhorn H, Tan KSW, Yoshikawa H. 2012. Blastocystis: pathogen or passenger?: An evaluation of 101 years of research. Springer, Heidelberg Berlin.

Natalia F, Suwanti LT, Suprihati E, Koesdarto S, Srianto P. 2018. Morphological detection of the intestinal parasite Blastocystis Sp. in fresh and cultured feces of pet Sugar Glider (Petaurus Breviceps) (Mammalia: Marsupialia: Petauridae) in Surabaya, Indonesia. Philipp J Vet Med 55 (SI): 91-96.

Osman M, El Safadi D, Cian A, Benamrouz S, Nourrisson C, Poirier P, Pereira B, Razakandrainibe R, Pinon A, Lambert C, Wawrzyniak I. 2016. Prevalence and risk factors for intestinal protozoan infections with Cryptosporidium, Giardia, Blastocystis and Dientamoeba among schoolchildren in Tripoli, Lebanon. PLoS Neglected Trop Dis 10 (3): e0004496. DOI: 10.1371/journal.pntd.0004496.

Parija SC, Jeremiah SS. 2013. Blastocystis: Taxonomy, Biology and Virulence. Trop Parasitol 3 (1): 17-25. DOI: 10.4103/22295070.113894

Ragavan ND, Govind SK, Chye TT, Mahadeva S. 2014. Phenotypic variation in Blastocystis sp. ST3. Parasites Vectors 7 (404): 1-10. DOI: 10.1186/1756-3305-7-404.

Ragavan ND, Kumar S, Chye TT, Mahadeva S, Shiaw-Hooi H. 2015. Blastocystis sp. in irritable bowel syndrome (IBS)-Detection in stool aspirates during colonoscopy. PLoS ONE 10 (9): e0121173. DOI: 10.1371/journal.pone.0121173.

Roberts T, Stark D, Harkness J, Ellis J. 2014. Update on the pathogenic potential and treatment options for Blastocystis sp. Gut Pathog 6: 17. DOI: 10.1186/1757-4749-6-17.

Skotarczak B. 2018. Genetic diversity and pathogenicity of Blastocystis. Ann Agric Environ Med 25 (3): 411-416. DOI: 10.26444/aaem/81315.

Suresh K, Howe J, Chong SY, Ng GC, Ho LC, Loh AK, Ramachandran NP, Yap EH, Singh M. 1994. Ultrastructural changes during in vitro encystment of Blastocystis hominis. Parasitol Res 80: 327-335. DOI: 10.1007/BF02351875

Suwanti LT, Mufasirin, Lastuti NDR. 2020a. Molecular detection and morphological varied of Blastocystis sp in beef cattle in Siak Sri Indrapura Riau Indonesia. Eco Environ Cons 26 (April Suppl. Issue): S209- S212.

Suwanti LT, Susana Y, Hastutiek P, Suprihati E, Lastuti ND. 2020 b. Blastocystis spp. subtype 10 infected beef cattle in Kamal and Socah, Bangkalan, Madura, Indonesia. Vet World 13 (2): 231-237. DOI: 10.14202/vetworld.2020.231-237.

Tan TC, Suresh KG, Smith HV. 2008. Phenotypic and genotypic characterization of Blastocystis hominis isolates implicates subtype 3 as a subtype with pathogenic potential. Parasitol Res 104: 85-93. DOI: $10.1007 / \mathrm{s} 00436-008-1163-5$

Wawrzyniak I, Poirier P, Viscogliosi E, Dionigia M, Texier C, Delbac F, Alaoui HE. 2013. Blastocystis, an unrecognized parasite: An overview of pathogenesis and diagnosis. Ther Adv Infect Dis 1(5): 167-178. DOI: $10.1177 / 2049936113504754$ 
Yason JA, Tan KSW. 2018. Membrane surface features of Blastocystis Subtypes. Genes 9: 1-6. DOI: 10.3390/genes9080417.

Zaman V, Howe J, Ng M, Goh TK. 1999. Scanning Electron Microscopy of the surface coat of Blastocystis hominis. Parasitol Res 85: 974-976. DOI: $10.1007 / \mathrm{s} 004360050668$
Zhang X, Qiao JY, Zhou XJ, Yao FR, Wei ZC. 2007. Morphology and reproductive mode of Blastocystis hominis in diarrhea and in vitro. Parasitol Res 101 (1): 43-51. DOI: 10.1007/s00436-006-0439-X.

Zhang X, Zhang S, Qiao J, Wu X, Zhao L, Liu Y, Fan X. 2012. Ultrastructural insights into morphology and reproductive mode of Blastocystis hominis. Parasitol Res 110: 1165-1172. DOI: 10.1007/s00436-011-2607-x. 